
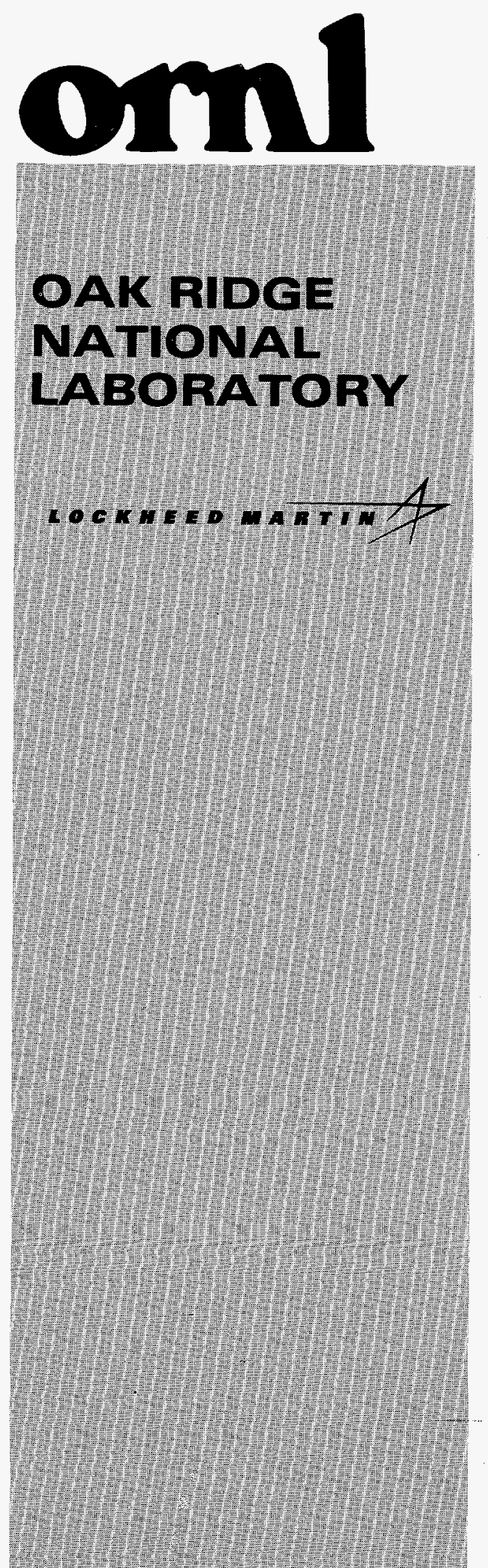

WANAGED NNO OPERATEO BY

LOCKHEED MARMN ENERGY RESEARCH CORPORATION FOR THE UNTEO STATES

DEPARTMENT OF ENERGY

\section{Quality Assurance Plan for the High Level Controller for the CBMS Block II}

\author{
RECEIVED \\ OCT 081997 \\ OSTI
}

R. W. Reid

I. F. Robbins

K. A. Stewart

C. L. Terry

R. A. Whitaker

D. A. Wolf

J. C. Zager

\section{MASTER N}

DISTAIBUTION OF THIS DOCUMENT IS UNLMITED 
This report has been reproduced directly from the best available copy.

Available to DOE and DOE contractors from the Office of Scientific and Technical Information, P. O. Box 62, Oak Ridge, TN 37831; prices available from (423) 576-8401, FTS 626-8401.

Available to the public from the National Technical Information Service, U.S. Department of Commerce, 5285 Port Royal Road, Springfield, VA 22161.

This report was prepared as an account of work sponsored by an agency of the United States Government. Neither the United States Government nor any agency thereof, nor any of their employees, makes any warranty, express or implied, or assumes any legal liability or responsibility for the accuracy, completeness, or usefulness of any information, apparatus, product, or process disclosed, or represents that its use would not infringe privately owned rights. Reference herein to any specific commercial product, process, or service by trade name, trademark, manufacturer, or otherwise, does not necessarily constitute or imply its endorsement, recommendation, or favoring by the United States Government or any agency thereof. The views and opinions of authors expressed herein do not necessarily state or reflect those of the United States Government of any agency thereof. 


\section{DISCLAIMER}

Portions of this document may be illegible electronic image products. Images are produced from the best available original document. 


\title{
QUALITY ASSURANCE PLAN \\ FOR THE \\ HIGH LEVEL CONTROLLER FOR THE CBMS BLOCK II
}

\author{
R. W. Reid \\ I. F. Robbins \\ K. A. Stewart \\ C. L. Terry \\ R. A. Whitaker \\ D. A. Wolf \\ J. C. Zager
}

Date Published: September 1997

Prepared by the Oak Ridge National Laboratory

Oak Ridge, Tennessee 37831

Managed by

LOCKHEED MARTIN ENERGY RESEARCH CORP.

for the

U.S. DEPARTMENT OF ENERGY

under contract DE-AC05-96OR22464 


\section{CONTENTS}

QUALITY POLICY $\ldots \ldots \ldots \ldots \ldots \ldots \ldots \ldots \ldots \ldots \ldots \ldots \ldots \ldots \ldots \ldots$

ACRONYMS AND ABBREVIATIONS $\ldots \ldots \ldots \ldots \ldots \ldots \ldots \ldots \ldots$ ix

ABSTRACT $\ldots \ldots \ldots \ldots \ldots \ldots \ldots \ldots \ldots \ldots \ldots \ldots \ldots \ldots \ldots \ldots \ldots \ldots \ldots \ldots$

1. INTRODUCTION $\ldots \ldots \ldots \ldots \ldots \ldots \ldots \ldots \ldots \ldots \ldots \ldots \ldots \ldots \ldots \ldots \ldots \ldots$

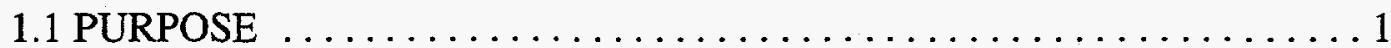

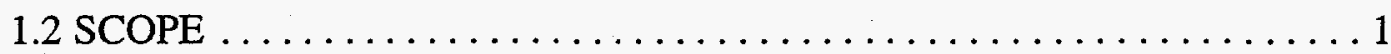

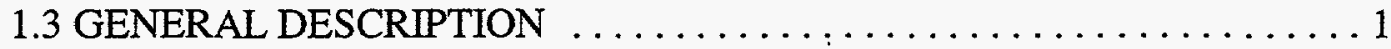

1.4 QUALITY ASSURANCE REFERENCES AND REQUIREMENTS . . . . . 1

2. ORGANIZATION AND MANAGEMENT $\ldots \ldots \ldots \ldots \ldots \ldots \ldots \ldots \ldots \ldots$

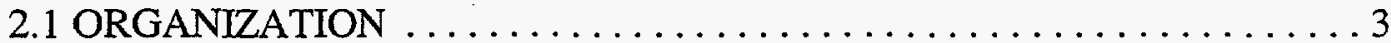

2.2 QA TASKS AND RESPONSIBILITIES $\ldots \ldots \ldots \ldots \ldots \ldots \ldots \ldots$

2.2.1 Software Manager . . . . . . . . . . . . . . . . . . . 3

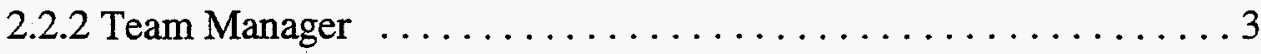

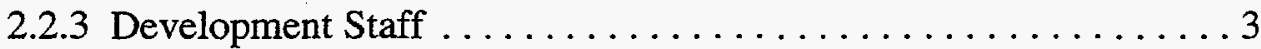

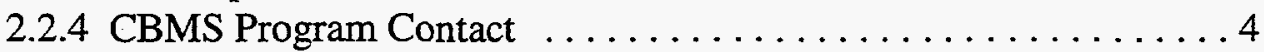

2.2.5 Quality Assurance Specialist . . . . . . . . . . . . 4

2.3 PROJECT TEAM MEMBERS . . . . . . . . . . . . . . . . 4

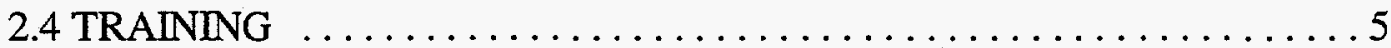

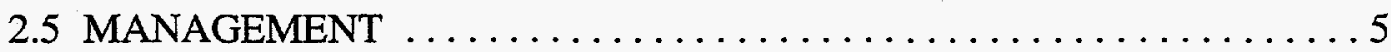

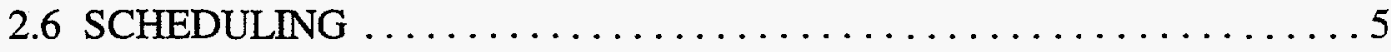

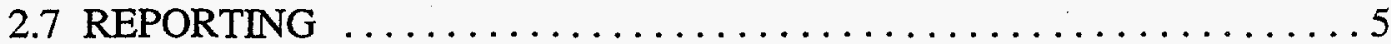

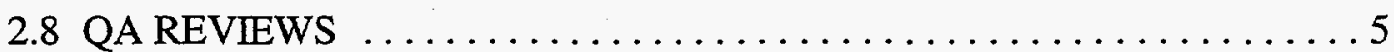

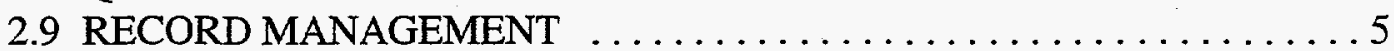

3. SOFTWARE DEVELOPMENT METHODOLOGY $\ldots \ldots \ldots \ldots \ldots \ldots \ldots \ldots$

3.1 SOFTWARE METHODOLOGY $\ldots \ldots \ldots \ldots \ldots \ldots \ldots \ldots \ldots$

3.2 VERIFICATION AND VALIDATION $\ldots \ldots \ldots \ldots \ldots \ldots \ldots \ldots \ldots$

3.3 SOFTWARE TOOLS AND TECHNIQUES $\ldots \ldots \ldots \ldots \ldots \ldots \ldots \ldots$

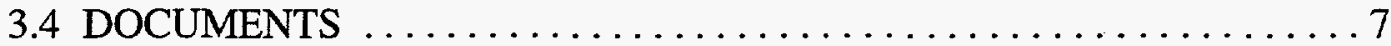

4. RISK MANAGEMENT $\ldots \ldots \ldots \ldots \ldots \ldots \ldots \ldots \ldots \ldots \ldots \ldots$

$4.1^{-}$RISK MANAGEMENT APPROACH ................ 9

4.2 REVIEW SCHEDULE $\ldots \ldots \ldots \ldots \ldots \ldots \ldots \ldots \ldots \ldots \ldots \ldots$

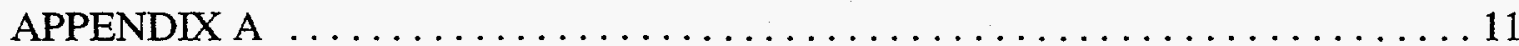

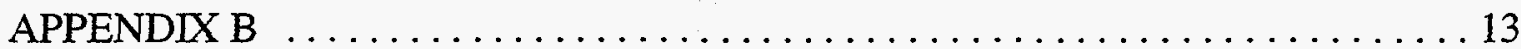




.




\section{QUALITY ASSURANCE PLAN \\ FOR THE}

HIGH LEVEL CONTROLLER FOR THE CBMS BLOCK II

The following signatures indicate acceptance, concurrence, and support of this Quality

Assunance Plam.

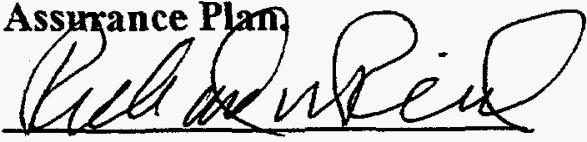

Dick Reid, CPED Team Manager

Oak Ridge National Laboratory
Date: $9 / 29 / 97$
Yene I Robbins

I. F. Robbins, Software Manager

Oak Ridge National Laboratory

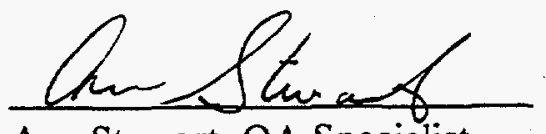

Ann Stewart, QA Specialist

Data Systems Research and Development

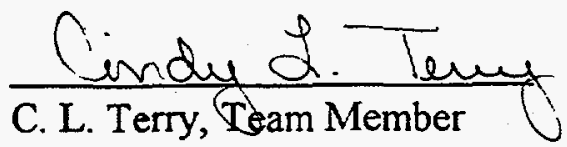

Oak Ridge National Laboratory

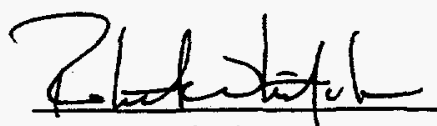

R. A. Whitaker, Team Member

Oak Ridge National Laboratory

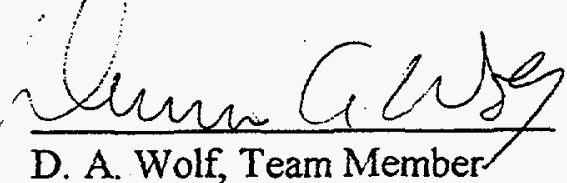

Oak Ridge National Laboratory

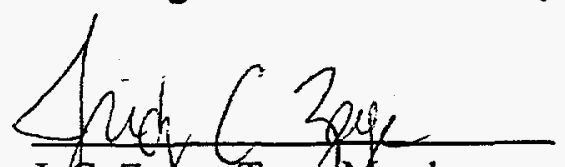

J.C. Zayer, Tean Member

Oak Ridge National Laboratory
Date: $9 / 29 / 8>$

Date: $9 / 29 / 97$
Date: $9129 / 97$

Date: $9 / 29 / 47$ 



\section{QUALITY POLICY FOR THE \\ HIGH LEVEL CONTROLLER FOR THE CBMS II}

It is the policy of the HLC/CBMS-II project to support the ORNL CRE Directorate goal of producing quality software by applying quality assurance processes in a risk-based, graded approach and to execute activities to successfully achieve project objectives. The team will support the CBMS Program Policy as described in the CBMS Program QAP and adopt and implement the applicable policies, procedures, and Quality Assurance Programs of DOE, LMER, CRE, and the CBMS Program. 


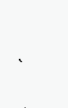




\section{ACRONYMS AND ABBREVIATIONS}

CASD

CBDCOM

CBMS

CBMS Program

CPED

CRE

CSMD

DOE

GUI

HLC

HLC/CBMS-II

I\&CD

LMER

LSD

ORNL

QA

QAP

SPP
Chemical and Analytical Sciences Division

Chemical and Biological Defense Command

Chemical and Biological Mass Spectrometer

Chemical and Biological Mass Spectrometer - Block II Program

Computational Physics and Engineering Division

Computing, Robotics, and Education

Computer Science and Mathematics Division

U.S. Department of Energy

Graphical User Interface

High Level Controller

High Level Controller for the Chemical and Biological Mass

Spectrometer Block II

Instrumentation and Controls Division

Lockheed Martin Energy Research Corporation

Life Sciences Division

Oak Ridge National Laboratory

quality assurance

quality assurance plan

standard practice procedure 
. 


\begin{abstract}
This document establishes the software Quality Assurance Plan (QAP) for the High Level Controller for the Chemical and Biological Mass Spectrometer Block II (HLC/CBMS-II) project activities under the Computing, Robotics, and Education (CRE) Directorate management. It defines the requirements and assigns responsibilities for ensuring, with a high degree of confidence, that project objectives will be achieved as planned.
\end{abstract}

The QAP outlined herein is responsive to and meets the Quality Assurance Program standards for the U.S. Department of Energy (DOE), Lockheed Martin Energy Research (LMER) Corporation, the Oak Ridge National Laboratory (ORNL), the ORNL CRE Directorate, and the Chemical and Biological Mass Spectrometer (CBMS) Block II Program. This document is intended to be in compliance with DOE Order 5700.6C, "Quality Assurance Program," and the ORNL Standard Practice Procedure, SPP X-QA-8, "Quality Assurance for ORNL Computing Software." This standard allows individual organizations to apply the stated requirements in a flexible manner suitable to the type of activity involved.

Section 1 of this document provides an introduction to the HLC/CBMS-II project QAP. Sections 2 and 3 describe the specific aspects of quality assurance as applicable to the project. Section 4 reviews the project approach to risk management.

The Risk Management Matrix given in Appendix A is a tool to assess, prioritize, and prevent problems before they occur; therefore, the matrix will be reviewed and revised on a periodic basis.

Appendix B shows the quality assurance criteria of the DOE Order $5700.6 \mathrm{C}$ and their applicability to this project. 


\section{INTRODUCTION}

\subsection{PURPOSE}

The purpose of this Quality Assurance Plan (QAP) is to provide the necessary guidance to ensure and formally demonstrate that the HLC/CBMS-II project satisfies its contractual requirements and performs according to the approved project specification documents. The QAP intent is to establish formal quality assurance (QA) methods and to implement sound practices, such as independent monitoring and assessment.

\subsection{SCOPE}

The QA requirements of this document apply to the HLC/CBMS-II project of the CBMS Program and to all individuals and organizations contributing to and participating in this project. This document supports the QA requirements described in the Chemical and Biological Mass Spectrometer Block II Program Quality Assurance Plan, QAP-X-94CASD/CBMS-001.

\subsection{GENERAL DESCRIPTION}

The CBMS Program was awarded to ORNL by the U.S. Army Chemical and Biological Defense command, Aberdeen Proving Ground, Maryland, to design the next version (Block II) mass spectrometer for the detection and identification of chemical and biological warfare agents, to fabricate four engineering prototypes, and to construct eight preproduction units. Five ORNL divisions are tasked to perform the work: The Chemical and Analytical Sciences Division (CASD) is the program lead, with the Instruments and Controls Division (I\&CD), Computational Physics and Engineering Division (CPED), Computer Science and Mathematics Division (CSMD), and Life Sciences Division (LSD) participating. Refer to the CBMS Program QAP for the CBMS Program Organization chart.

CPED is responsible for the development of software that will allow instrument configuration and data analysis and for the development of algorithms to identify chemical and biological agents. CPED will develop a graphical user interface (GUT) to support these functions and provide an end-user interface in which these processes will be preconfigured and largely automated. CPED will be involved with system integration as well. Personnel from CSMD are working with CPED on the development of algorithms for the HLC/CBMSII.

\subsection{QUALITY ASSURANCE REFERENCES AND REQUIREMENTS}

The following standards, policies, and procedures provided guidance in the development of this document and are recommended as references: 
- DOE Order 5700.6C, "Quality Assurance Program";

- $\quad$ SPP X-QA-8, "Quality Assurance for ORNL Computer Software";

- QAP-X-96-CRE-001, "ORNL Computing, Robotics, and Education Directorate (CRE) Management Plan"; and

- QAP-X-94-CASD/CBMS-001, "Chemical and Biological Mass Spectrometer - Block II CBMS Program Quality Assurance Plan."

The software produced by the HLC/CBMS Block-II project has been designated for QA purposes as category 2 software. The ORNL SPP X-QA-8, "Quality Assurance for ORNL Computer Software," defines category 2 software as "software where failure will not cause the failure of a project or endanger personnel but whose failure will have a serious effect on project deliverables, projection schedules, and/or cost." 


\section{ORGANIZATION AND MANAGEMENT}

\subsection{ORGANIZATION}

The CBMS Program is staffed by personnel from five ORNL divisions. CPED is responsible for the analysis and instrument configuration software and associated user interface. The programming team consists of Systems Engineering and Technology Group staff. An independent Quality Assurance function is provided by Energy Systems, Data System Research and Development staff.

\subsection{QA TASKS AND RESPONSIBILITIES}

All project team members are expected to maintain responsibility for the quality of products and services designed and delivered for the support of this project. General quality-related task descriptions and responsible team members are listed below. Also, refer to Appendix A for preventive actions and responsible team members.

\subsubsection{Team Manager}

- Prepares monthly progress reports, project schedule, project management plan, and budget requests

- Participates in planning and briefing sessions as required

- $\quad$ Ensures that all QA tasks are incorporated into the project schedule

- Maintains responsibility for financial and contractual direction

- Assists in the development of the QAP and commits required resources to implement the plans

\subsubsection{Software Manager}

- $\quad$ Provides input to monthly progress reports, the project schedule, and the project management plan

- Monitors task progress and reports any known or suspected schedule deviation to the team manager

- Integrates project with the CBMS Program

- $\quad$ Participates in planning and briefing sessions as required

- Coordinates the development of external system interfaces

- Provides technical direction

- Schedules and ensures documentation of software reviews

\subsubsection{Development Staff}

- Reviews requirements of this QAP 
- Develops software in accordance with standards stated in this QAP

- Ensures that a process for configuration control is followed

- $\quad$ Ensures that test plans are followed

- Participates in reviews

\subsubsection{CBMS Program Contact}

- Resolves technical issues with sponsor

- Communicates sponsor's direction to Software Manager and Development Staff

- Integrates low level and high level controllers for the CBMS Program

- Resolves issues involving systems external to the project

- Participates with the software manager in the definition of the functional requirements of the system

- Obtains system data

- $\quad$ Prepares the Acceptance Test Plan

- Conducts periodic software reviews

\subsubsection{Quality Assurance Specialist}

- Participates in the development of internal project-specific plans and procedures that incorporate QA requirements

- Ensures that the project team is kept current and knowledgeable of QA requirements and provides guidance as required

- $\quad$ Performs reviews, approvals, and verification of documents and activities affecting quality according to the QAP

- Reviews or establishes planning milestones when additional QA planning or activities are required

- Ensures that official copies of all QA records are kept in accordance with ORNL $\mathrm{X}-\mathrm{AD}-8$

\subsection{PROJECT TEAM MEMBERS}

The following staff make up the project team:

$\begin{array}{ll}\text { CBMS Program Contact } & \text { K. J. Hart } \\ \text { CPED Team Manager } & \text { R. W. Reid } \\ \text { CPED Software Manager } & \text { I. F. Robbins } \\ \text { Developers } & \text { C. L. Terry } \\ & \text { R. A. Whitaker } \\ & \text { D. A. Wolf } \\ & \text { J. C. Zager } \\ \text { Quality Assurance Specialist } & \text { K. A. Stewart }\end{array}$




\subsection{TRAINING}

The HLC/CBMS-II team manager and software manager shall ensure that the team members who perform activities affecting quality receive adequate training to ensure that suitable proficiency is achieved and maintained throughout the life cycle of the project. They are also responsible for ensuring that the team members have attained the necessary technical training for project success.

\subsection{MANAGEMENT}

The HLC/CBMS- II project will be managed by the software manager, who is responsible for the technical aspects of the project and will work closely with the CPED team manager. The software manager is responsible for integrating the project with the CBMS Program. The quality assurance specialist will maintain responsibility for conducting $Q A$ reviews and certifying the quality of project deliverables as a function independent of development.

\subsection{SCHEDULING}

The schedule for performing QA functions will be established in conjunction with the project's development schedule. From this schedule it will be possible to identify the resources required to effectively support the required QA activities. Major milestone events will be signified by the completion, submission, and official review of deliverables.

\subsection{REPORTING}

The progress and status of the project, and the completion of milestones, will be communicated to program management and the sponsor through monthly progress reports, division highlights, development meetings, briefings, and other methods as required and deemed necessary.

\subsection{QA REVIEWS}

A QA review will be conducted upon the completion of each major milestone and deliverable. This review will utilize a predefined checklist of QA activities based on the requirements of this plan. The completed checklist will be placed in the project files.

\subsection{RECORD MANAGEMENT}

Project QA records will be retained in the CBMS Program Office for the lifetime of the project plus 10 years. Duplicates will be filed in the HLC/CBMS-II project office. The following is a QA record:

Quality Assurance Plan for the High Level Controller (HLC) for the CBMS Block II. 



\section{SOFTWARE DEVELOPMENT METHODOLOGY}

\subsection{SOFTWARE METHODOLOGY}

The software development methodology that will be followed for the HLC/CBMS-II project is the Evolutionary Spiral Model. In the Spiral Model a partial system is developed, evaluated, and refined as necessary as an iterative process. Each iteration follows the same cycle: collect requirements, design the system, implement the design, and evaluate the product. The hands-on evaluation of the partial system is used to feed into the requirements for the next iteration. The key benefit of the Spiral Model is the ability to quickly address requirements, develop a partial system based on these requirements, then react to user feedback. As iterations are completed, the partial system is shaped into a completed system that has a greater probability of meeting the user's needs than traditional methodologies.

\subsection{VERIFICATION AND VALIDATION}

Verification can be defined as a set of activities to ensure that software correctly implements a specific function. The primary method of software verification used throughout this project will consist of functional testing by the developer and software reviews by the software manager and team members. Because of the size of the project team, functional testing and software reviews were determined to be the most effective methods of verification to ensure the correctness and quality of the software products developed.

Validation of the system refers to a set of activities that ensures that all system requirements have been met. Validation methods are described in the "Test Plan for the High Level Controller for the CBMS."

\subsection{SOFTWARE TOOLS AND TECHNIQUES}

The operating and analysis software for the HLC/CBMS-II will be written in $\mathrm{C}++$ on a Windows NT platform using Borland's GUI development product, $\mathrm{C}++$ Builder. The code will adhere to $\mathrm{C}++$ standards developed for the project and will be controlled according to the "HLC/CBMS-II Configuration Management Plan." The system will incorporate the GigaSoft ProEssentials Graphics Package.

\subsection{DOCUMENTS}

The following life cycle documents will be developed:

1. Functional Design Document,

2. Test Plan,

3. Configuration Management Plan, and

4. User Manual. 


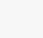




\section{RISK MANAGEMENT}

\subsection{RISK MANAGEMENT APPROACH}

Determining potential problems and taking actions to minimize their impact on the project are primary goals of this QA program. The Risk Assessment Matrix listed in Appendix A is the result of identifying and prioritizing problems. The matrix lists each potential problem with its associated cause and its effect on the project. Each problem was assigned a probability of occurring, designated as low $(0-30 \%)$, medium (31-50\%), medium high (51$60 \%$ ), and high $(61-100 \%)$. Also assigned to each problem was a risk-to-the-project factor: low (no or minimal impact), medium (minor schedule delays or budget increases), medium high (major schedule delays or budget increases), or high (may cause project failure). Specific preventive actions to address each problem were then determined and listed, with the responsible person and schedule indicated.

\subsection{REVIEW SCHEDULE}

The Risk Assessment Matrix will be reviewed and updated periodically. The software manager ensures that the actions are incorporated in the project schedule. The QA specialist will review the actions during QA reviews. 
; 
APPENDIX A

Quality Assurance Risk Assessment Matrix

for the

High Level Controller (HLC) for the CBMS Block II

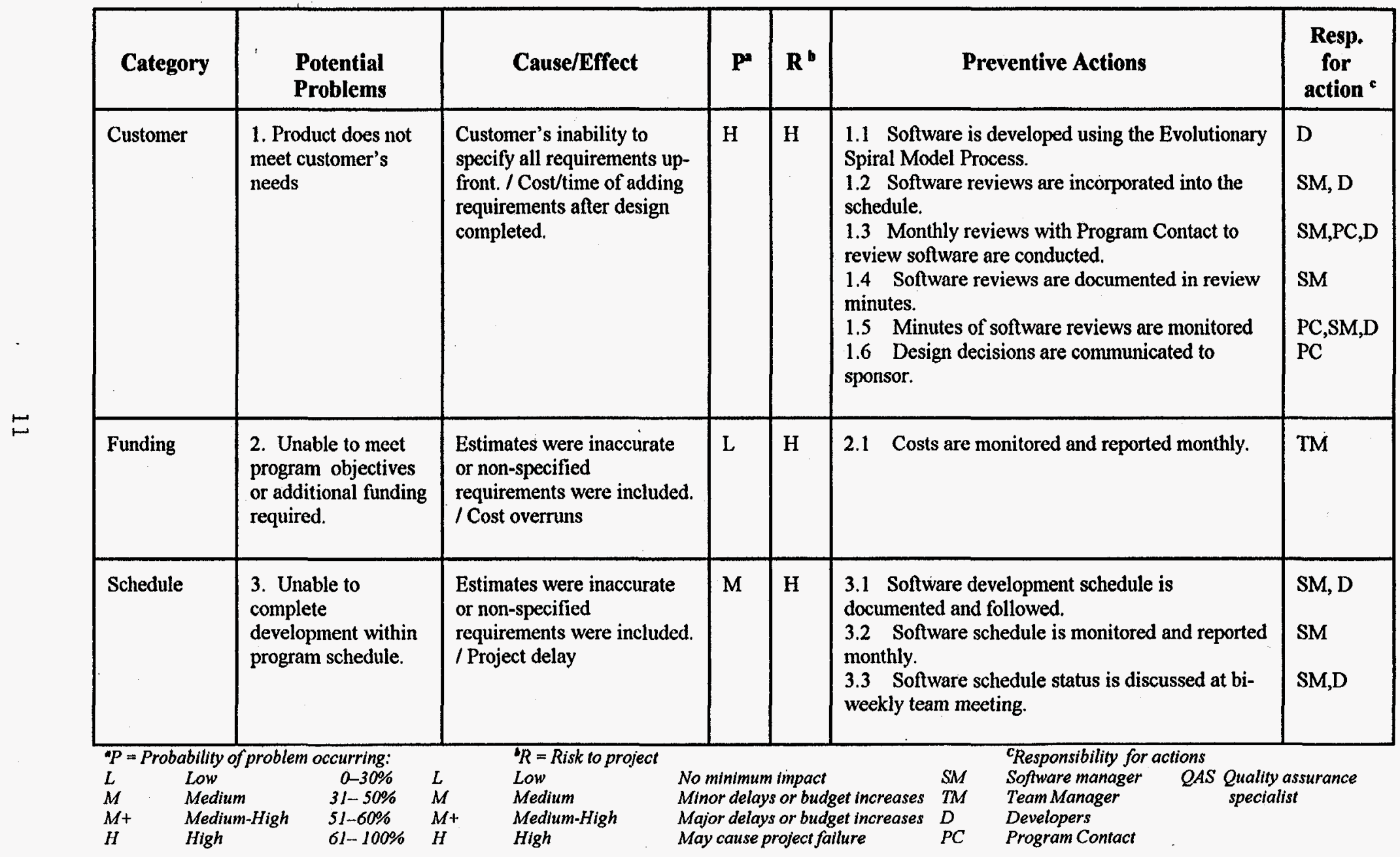


APPENDIX A (Continued)

\begin{tabular}{|c|c|c|c|c|c|c|}
\hline Category & Potential Problems & Cause/Effect & $\mathbf{p}^{\mathfrak{a}}$ & $\mathbf{R} \cdot$ & Preventive Actions & $\begin{array}{l}\text { Resp.e } \\
\text { for } \\
\text { action }\end{array}$ \\
\hline Software & $\begin{array}{l}\text { 4. Unable to test } \\
\text { adequately }\end{array}$ & $\begin{array}{l}\text { Over ambitious schedule } \\
\text { / Deliverable is } \\
\text { compromised }\end{array}$ & $\mathbf{M}$ & $\mathbf{H}$ & $\begin{array}{l}\text { 4.1 Test plan is developed. } \\
4.2 \text { Schedule adequate test time based on test } \\
\text { plan and document in project schedule. }\end{array}$ & $\begin{array}{l}\text { SM } \\
\text { SM }\end{array}$ \\
\hline & $\begin{array}{l}\text { 5. Ineffective } \\
\text { communications or } \\
\text { miscommunications } \\
\text { between team } \\
\text { members. }\end{array}$ & $\begin{array}{l}\text { Size of team / Delays in } \\
\text { schedule or requirements } \\
\text { not satisfied }\end{array}$ & L & $M$ & $\begin{array}{l}\text { 5.1 The team meets bi-weekly. } \\
5.2 \text { Configuration Management Plan is } \\
\text { developed. } \\
5.2 \text { Configuration control process is } \\
\text { followed. }\end{array}$ & $\begin{array}{l}D \\
\text { SM } \\
D\end{array}$ \\
\hline & $\begin{array}{l}\text { 6. Interface } \\
\text { between processors } \\
\text { functions } \\
\text { incorrectly. }\end{array}$ & $\begin{array}{l}\text { Teams working in } \\
\text { different divisions and on } \\
\text { different aspects of the } \\
\text { instrument / Delays in } \\
\text { schedule or requirements. }\end{array}$ & $\mathbf{M}$ & $\mathbf{H}$ & $\begin{array}{l}\text { 6.1 Monthly interdivisional meeting } \\
\text { conducted with team and/or software } \\
\text { managers for all involved divisions are held. } \\
6.2 \text { Interface between high and low level } \\
\text { processors is documented. } \\
6.3 \text { Documentation is reviewed and followed }\end{array}$ & $\begin{array}{l}\text { PC } \\
\text { PC } \\
\text { SM,D }\end{array}$ \\
\hline $\begin{array}{ll}P=\text { Probability } \\
& \text { Low } \\
\text { M } & \text { Medi } \\
M_{+} & \text {Medi } \\
H & \text { High }\end{array}$ & 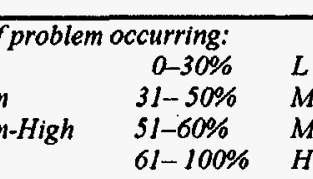 & $\begin{array}{ll}R=\text { Risk to project } & \\
\text { Low } & \text { Non } \\
\text { Medium } & \text { Minc } \\
\text { Medium-High } & \text { Majc } \\
\text { High } & \text { May }\end{array}$ & mum & mpact & \multicolumn{2}{|c|}{$\begin{array}{l}\text { Responsibility for actions } \\
\text { Software manager QAS Quality assurance } \\
\text { TeamManager } \quad \text { specialist } \\
\text { Developers } \\
\text { Program Contact }\end{array}$} \\
\hline
\end{tabular}


APPENDIX B

Applicability of DOE 5700.6C Criteria to the

High Level Controller (HLC) for the CBMS Block II

\begin{tabular}{|c|c|c|}
\hline DOE 5700.6C CRITERIA & $\begin{array}{l}\text { RELEVANT SECTION OF THIS } \\
\text { QAP }\end{array}$ & COMMENTS \\
\hline Program & $1.0,2.0$ & \\
\hline Personnel Training and Qualification & 2.3 & \\
\hline Documents and Records & $2.7,3.4$ & \\
\hline Quality Improvement & 4.2 & $\begin{array}{l}\text { Continuous improvement through } \\
\text { frequent reviews }\end{array}$ \\
\hline Work Processes & 3.0 & $\begin{array}{l}\text { Work processes are controlled } \\
\text { through reviews and the V\&V } \\
\text { process. }\end{array}$ \\
\hline Design & 3.1 & $\begin{array}{l}\text { Design of software is in accordance } \\
\text { with the Spiral Model. }\end{array}$ \\
\hline Procurement & na. & Not applicable \\
\hline Inspection and Acceptance Testing & $2.6,3.2$ & \\
\hline Management Assessment & 2.6 & $\begin{array}{l}\text { Management assessment through } \\
\text { project reviews }\end{array}$ \\
\hline Independent Assessment & 2.6 & Independent QA function \\
\hline
\end{tabular}




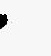




\section{INTERNAL DISTRIBUTION}

1. W. H. Griest

2. K. J. Hart

3. M. A. Kuliasha

4. D. H. Pike

5. R. W. Reid

6-8. I. F. Robbins

9. K. A. Stewart

10. C. L. Terry
11. R. A. Whitaker

12. D. A. Wolf

13. J. C. Zager

14. J. C. Davis

15. L. A. James

16. Central Research Library

17. Laboratory Records, ORNL-RC

18-19. Laboratory Records for submission to Office of Scientific and Technical Information 